\title{
Peningkatan Kinerja Pemasaran UMKM Melalui Dimensi Kewirausahaan di Kabupaten Kerinci
}

\author{
Edia Satria ${ }^{1}$, Ida Yusnita ${ }^{2}$, Ayu Esteka Sari $^{3}$ \\ ${ }^{1,2,3}$ STIE Sakti Alam Kerinci, Jambi, Indonesia \\ *Correspondence email: ediasatria85@gmail.com; idayusnita2020@gmail.com; ayuesteka82@gmail.com
}

\begin{abstract}
Entrepreneurship is believed to be a tool to encourage economic growth to solve other economic problems, such as unemployment, poverty and social inequality. Micro, Small and Medium Enterprises is a business that plays an important role in the national economy. The success of the marketing of Micro, Small and Medium Enterprises is influenced by the dimension of entrepreneurship. The dimensions of entrepreneurship used in this study are economic entrepreneurship, resource-based entrepreneurship and human capital entrepreneurship. Respondents in this study were actors of Micro, Small and Medium Enterprises (MSMEs) in Gunung Raya Subdistrict, Kerinci Regency as many 100 respondents. The Model Testing Technique in this study used the Structural Equation Model (SEM) using AMOS. The results showed that the Entrepreneurship Dimension had a positive and significant effect on the Market Performance of MSMEs. The magnitude of the influence of entrepreneurship Dimension on Market Performance of MSMEs is 0.231 or 23.1\%, so it is necessary to support entrepreneurship Dimension to increase the Market Performance of MSMEs.
\end{abstract}

Keywords: Entrepreneurship, Market Performance, Micro, Small and Medium Enterprises, Economic entrepreneurship, Human capital entrepreneurship.

\section{Pendahuluan}

Pengurangan kemiskinan semakin menjadi subjek inti bagi seluruh Negara. Para peneliti dalam lintas ilmu sosial mulai dari ekonomi dan keuangan, hingga manajemen dan kewirausahaan. Salah satu strategi untuk solusi memberantas kemiskinan adalah meningkatkan kagiatan usaha yaitu peningkatan pertumbuhan Usaha Mikro Kecil Dan Menengah (UMKM). Dimana Usaha Mikro Kecil Dan Menengah (UMKM) diprakarsai oleh jiwa kewirausahaan. Para peneliti semakin menyadari bahwa kewirausahaan merupakan bagian penting untuk solusi dari kemiskinan di seluruh dunia (Alvarez Barmey, dan Newman, 2015). Tetapi tantangan berikutnya adalah untuk lebih memahami hubungan kewirausahaan dengan pengurangan kemiskinan dan bagaiamana membuat dan mendorong kewirausahaan menjadi produktif.

Pertumbuhan wirausaha Indonesia berpotensi terus meningkat dengan dukungan berbagai pihak di mana wirausaha memiliki kesempatan dan kemampuan berwirausaha. Pemerintah Indonesia telah mendorong tumbuhnya aktivitas kewirausahaan. Secara umum kemiskinan dan bisnis kewirausahaan mencakup banyak topik yang perspektif. Steven Si, David Ahlstrom, Jiang Wei \& John Cullen (2019) menyatakan dengan perspektif remdiasi merupakan perspektif bahwa kewirausahaan dapat mengurangi kemiskinan ketika sumberdaya dan modal bisa dikelola dan ditangani secara baik. Perspektif ini memiliki beberapa asumsi mendasar yang mendasari dalam hal ini melihat bahwa kemiskinan terjadi karena adanya sumber daya yang langka, seperti kekurangan modal dan aset fisik lainnya.

Pemerintah Kabupaten Kerinci melalui Dinas Koperasi dan Usaha Mikro Kecil Dan Menengah (UMKM) menjadi salah satu pilar yang diharapkan mampu mendukung ekonomi kerakyatan di Kabupaten Kerinci. Dengan dukungan potensi sumber daya alam dan sumber daya manusia diharapkan kegiatan pembangunan UMKM di Kabupaten Kerinci mampu menggerakkan roda perekonomian yang bertujuan untuk kesejahteraan masyarakat. Peranan UMKM dalam perekonomian daerah sangat penting karena mampu menyerap sebagian besar tenaga kerja sehingga dapat mewujudkan pemerataan berusaha dan pemerataan pendapatan. Sampai tahun 2013 jumlah Koperasi di Kabupaten Kerinci sebanyak 191 unit, dan jumlah tersebut terus meningkat setiap tahunnya, Usaha Mikro Kecil Dan Menengah (UMKM) binaan Dinas Koperasi dan Kabupaten Kerinci adalah sebanyak 3.433 unit. Salah satu cara peningkatan dari kinerja UMKM dengan pembinaan yang intensif akan menghasilkan UMKM dapat tumbuh, kuat, besar, mandiri, yang memiliki sumber daya manusia, manajemen, penguasaan tekhnologi yang tinggi dan berkualitas. Dengan meningkatkan kerjasama antar UMKM atau dengan usaha lainnya, dan dukungan fasilitasi baik dalam meningkatkan kualitas sumber daya manusia, kelembagaan dan usaha serta kemudahan UMKM dalam mengakses perizinan maupun permodalan melalui pelayanan yang cepat, mudah dan murah. Dibutuhkan lah jiwa kewirausahan yang handal dan tangguh. Melalui berbagai dimensi kewirausahaan. Kesuksesan sebuah UMKM tergantung pada bagaimana hubungan UMKM itu dengan lingkungannya. Lingkungan persaingan mempengaruhi jumlah dan jenis pesaing yang harus dihadapi manajer pemasaran dan bagaimana mereka akan berperilaku. Sehingga dibutuhkan peningkatan kinerja dari pemasaran dari UMKM.

Penelitian ini bertujuan untuk meningkatkan kinerja pemasaran usaha mikro kecil dan menengah (UMKM) 
melalui dimensi kewirausahaan di Kabupaten Kerinci. Peningkatan pengelolaan usaha mikro kecil dan menengah (UMKM) akan berdampak Terhadap peningkatan Kesejahteraan Dan Pendapatan Masyarakat Kabupaten Kerinci secara umumnya.

\section{Kinerja Pemasaran}

Kinerja pemasaran sebagai ukuran bisnis dari tingkat keberhasilan perusahaan termasuk omset penjualan, jumlah pelanggan, penjualan dan pertumbuhan profitabilitas (Naila, 2016). Indikator pengukuran kinerja dan keunggulan bersaing yang paling sering digunakan adalah market share dan profitabilitas. Kinerja perusahaan dapat juga menggunakan pangsa pasar (market share) sebagai indikator pengukuran kinerja perusahaan yang kemudian dilengkapi dengan pertumbuhan pangsa pasar (market share growth). Market share adalah pengukuran kinerja pemasaran atau kinerja operasional yang dapat membedakan antara pemenang dan pecundang. Saeko et al (2012) menyatakan kinerja pemasaran adalah kunci keberhasilan bisnis sebagai hasil dari strategi pasar untuk pelanggan, pasar, dan organisasi keuangan ini, kinerja pasar seperti pertumbuhan penjualan, pangsa pasar dan pengembangan pasar dalam studi kinerja pemasaran. Studi lain menunjukkan bahwa kinerja pemasaran yang baik dinyatakan dalam tiga fokus utama sebagai berikut nilai penjualan, pertumbuhan penjualan dan pangsa pasar yang akhirnya mampu meningkatkan laba perusahaan (Ferdinand, 2005)

\section{Usaha Mikro Kecil dan Menengah (UMKM)}

Usaha Mikro Kecil Dan Menengah (UMKM) merupakan sektor usaha yang telah terbukti berperan strategis atau penting dalam mengatasi akibat dan dampak dari krisis ekonomi yang pernah melanda Indonesia di tahun 1997. Di sisi lain, sektor usaha kecil dan informal juga telah mampu memberikan kontribusi dalam mendorong pertumbuhan ekonomi Indonesia selama ini. Kedudukan yang strategis dari sektor usaha kecil dan informal tersebut juga karena sektor ini mempunyai beberapa keunggulan dibandingkan usaha besar/menengah. Keunggulan-keunggulan sektor ini antara lain kemampuan menyerap tenaga kerja dan menggunakan sumberdaya lokal, serta usahanya relatif bersifat fleksibel.

Definisi UMKM menurut Undang-undang (UU) Nomor 20 Tahun 2008 tentang Usaha Mikro, Kecil dan Menengah. Usaha kecil didefinisikan sebagai kegiatan ekonomi produktif yang berdiri sendiri, yang dilakukan oleh orang perorangan atau badan usaha yang bukan merupakan anak perusahaan atau bukan cabang perusahaan yang dimiliki, dikuasai, atau menjadi bagian, baik langsung maupun tidak langsung, dari usaha menengah atau usaha besar, serta memenuhi kriteria antara lain: kekayaan bersih Rp.50 juta sampai Rp.500 juta tidak termasuk tanah dan bangunan tempat usaha, atau memiliki hasil penjualan tahunan Rp.300 juta sampai Rp.2,5 miliar. Sedangkan bagi usaha mikro, dimana usaha tersebut sebuah usaha produktif mili orang perorangan atau badan usaha perorangan, serta memenuhi kriteria antara lain: kekayan bersih paling banyak Rp.50 juta, atau memilki total omzet paling banyak Rp.300 juta per tahun. Dan terakhir usaha menengah yaitu, usaha ekonomi produktif yang berdiri sendiri, yang dilakukan oleh orang perseorangan atau badan usaha yang bukan merupakan anak perusahaan atau cabang perusahaan yang dimiliki, dikuasai, atau menjadi bagian baik langsung maupun tidak langsung dengan usaha kecil atau usaha besar. Serta memenuhi kriteria antara lain: kekayaan bersih Rp.500 juta sampai dengan Rp.10 miliar, atau memiliki hasil usaha penjualan tahunan lebih dari Rp.2,5 miliar sampai Rp.50 miliar.

\section{Dimensi Kewirausahaan}

Edwin, Hari dan Ilham (2013) mengatakan bahwa kewirausahaan adalah usaha untuk menciptakan nilai melalui kesempatan bisnis manajemen, pengambilan risiko yang tepat dan melalui keterampilan komunikasi dan manajemen untuk memobilisasi manusia, uang dan bahan- bahan baku atau sumber daya lain yang diperlukan untuk menghasilkan proyek supaya terlaksana dengan baik. Untuk melaksanakan proyek dengan baik diperlukan karakteristik dan sikap kewirausahaan yang mendukung sehingga usaha yang dilakukan berjalan dengan lancar. Rizwan et al (2019) berpendapat bahwa orang yang berpikiran wirausaha banyak percaya diri tentang keterampilan dan kemampuan mereka bahwa mereka melebih-lebihkan peluang kesuksesan mereka. Dengan demikian, wirausahawan menjadi kehilangan pemahaman dan menjadikannya efektif keputusan sebagai objektivitas untuk kebutuhan perubahan diatasi oleh subjektivitas. Kinerja Usaha Mikro Kecil Dan Menengah (UMKM) didukung oleh karakteristik kewirausahaan dan sikap kewirausahaan yang yang dimiliki oleh pengusaha. Semua itu merupakan hakekat dari kewirausahaan yang harus ada pada Usaha Mikro Kecil Dan Menengah (UMKM)

Dimensi Kewirausahaan menurut Timpeh (2011), adalah :

a. Economic entrepreneurship, merupakan wirausaha yang mengarahkan peran pengusaha dalam konteks produksi dan distribusi barang di pasar yang kompetitif

b. Psychological entrepreneurship, menekankan karakteristik pribadi yang mendefinisikan kewirausahaan. Karakter kepribadian perlu untuk pencapaian dalam pengambilan risiko, inovasi, dan toleransi.

c. Sociological entrepreneurship, teori sosiologis adalah yang ketiga dari teori kewirausahaan utama. Berfokus pada 
konteks social menganalisis secara tradisional. Empat konteks sosial yang berhubungan dengan peluang wirausaha yaitu jejaring sosial.

d. Anthropological entrepreneurship, penekanannya adalah pada model kewirausahaan budaya. Model mengatakan bahwa usaha baru dibuat oleh pengaruh budaya seseorang. Praktek budaya mengarah pada sikap kewirausahaan seperti inovasi juga menyebabkan perilaku penciptaan usaha. Etnis individu mempengaruhi sikap dan perilaku.

e. Opportunity-based entrepreneurship, teori berbasis peluang yang menyediakan kerangka kerja konseptual yang luas untuk penelitian kewirausahaan, Pengusaha tidak menyebabkan perubahan tetapi mengeksploitasi peluang yang berubah.

f. Resource-based entrepreneurship, teori kewirausahaan berbasis sumber daya berpendapat bahwa akses ke sumber daya berbasis peluang dan pertumbuhan usaha barumenekankan pentingnya sumber daya keuangan, sosial dan manusia

g. Human capital entrepreneurship, wirausaha memiliki sumber daya spesifik perorangan yang memfasilitasi peluang baru dan pengumpulan sumber daya baru untuk usaha yang sedang dilakukan, beberapa orang lebih mampu mengenali dan memanfaatkan peluang daripada yang lain karena mereka memiliki akses yang lebih baik ke informasi dan pengetahuan

\section{Peningkatan Kinerja Pemasaran UMKM melalui Dimensi Kewirausahaan}

Kemampuan kewirausahaan merupakan orientasi kewirausahaan memiliki lima aspek, yaitu otonomi, inovasi, pengambilan risiko, keaktifan pro dan agresivitas kompetitif akan memacu usaha secara aktif kedepannya dan untuk memanfaatkan peluang pasar sebelum yang lain dapat menciptakan peluang baru Wincent et al (2014). Orientasi wirausaha yang baik akan dapat meningkatkan kemampuan pasar, jiwa wirausaha memiliki kemampuan sumber daya yang unik dan dapat meningkatkan Usaha yang berada di bawah efisiensi penggunaan sumber daya dan penyebaran kemampuan berwirausaha (Paulina \& Wardoyo, 2012). Orientasi kewirausahaan yang lebih tinggi dapat menciptakan kemampuan pasar yang lebih tinggi (Haroon, M \& Kocak, A. 2011). State of The Art pada Penelitian ini adalah dengan menggunakan dimensi kewirausahaan dari Timpeh (2011) menjadi konsep dan teori yang menjadi dasar penelitian untuk faktor-faktor yang mempengaruhi kinerja pemasaran UMKM.

\section{Metode}

Penelitian ini dilaksanakan pada UMKM yang ada Kabupaten Kerinci Propinsi Jambi dengan studi kasus berada di Kecamatan Gunung Raya. Waktu penelitian di Bulan Agutus 2020. Populasi dari penelitian ini adalah seluruh Wirausaha yang ada Kabupaten Kerinci dengan studi kasus berada di Kecamatan Gunung Raya. Responden dalam penelitian ini adalah para pelaku Usaha Mikro Kecil Dan Menengah (UMKM). Metode penarikan sampel pada penelitin ini menggunakan Kuota Sampling, dengan teknik penarikan sampel dimana sampel dianggap cocok dan memiliki ciri tertentu yang diinginkan. Didapatkan jumlah sampel apda penelitian ini sebanyak 100 pelaku UMKM dari jenis kegiatan dan usaha yang berbeda beda. Data yang digunakan dalam penelitian ini adalah data primer, yaitu data yang diperoleh atau dikumpulkan secara langsung dari sumber datanya melalui wawancara (interview) dan daftar pertanyaan (questionaire) yang diberikan kepada responden yang dijadikan sampel. Penelitian ini menggunakan survey untuk mendapatkan data-data yang diperlukan. Cara yang digunakan adalah dengan wawancara (interview) dan menyebarkan daftar pertanyaan (questionaire) kepada responden.

Teknik Pengujian Model dalam penelitian ini menggunakan Stuctural Equation Model (SEM). Teknik Pengujian Model dalam penelitian ini menggunakan Stuctural Equation Model (SEM) dengan menggunakan AMOS Versi 21. SEM merupakan gabungan dua metode statistik yang terpisah yaitu analisis faktor (factor analysis) model persamaan simultan (simultaneous equation modeling) yang dikembangkan di ekonometrika, untuk menganalisis hubungan struktural model yang diusulkan. Kesesuaian model dievaluasi melalui telaah terhadap berbagai kriteria goodness-of-fit. Beberapa indeks kesesuaian dan cut-off value-nya yang digunakan untuk menguji apakah sebuah model diterima atau ditolak. Hasil penelitian ini diharapkan dapat memberikan gambaran yang signifikan atas Dimensi Kewirausahaan yang terdiri dari 3 dimensi yaitu economic entrepreneurship, Resource-based entrepreneurship dan human capital entrepreneurship. Dengan adanyad dimensi kewirausaan yang baik akan berakibat adanya Kreatifitas Strategi Pemasaran Sehingga Mampu Meningkatkan Kinerja pemasaran Usaha Mikro Kecil Dan Menengah (UMKM). Dengan semakin meningkatnya Kinerja Pemasaran UMKM maka berdampak terhadap peningkatan Pendapatan dan Kesejahteraan wirausaha pada UMKM. Secara umum akan meningkatkan pembangunan di Kabupaten Kerinci.

\section{Hasil}

Structural Equation Model (SEM) adalah teknik statistik untuk menguji dan memperkirakan kausal hubungan dengan mengintegrasikan analisis faktor dan jalur. SEM dapat memeriksa serangkaian hubungan ketergantungan secara bersamaan. Ini sangat berguna dalam menguji teori itu berisi beberapa persamaan yang melibatkan hubungan ketergantungan. SEM adalah pengembangan dari General Linier Model (GLM) dengan regresi berganda sebagai 
bagian utamanya. SEM lebih andal, ilustratif dan kuat daripada teknik regresi saat memodelkan interaksi, nonlinier, kesalahan pengukuran, korelasi istilah kesalahan dan korelasi antara beberapa independen variabel (Elizar, Suripin, \& Wibowo, 2017).

\section{Pengujian Model}

Tabel 1

Hasil Pengujian Model

\begin{tabular}{lll}
\hline No & \multicolumn{1}{c}{ Testing Fit } & \multicolumn{1}{c}{ Tingkat Kecocokan Yang Bisa Diterima } \\
\hline 1 & Absolute Fit Indices & Diterima Jika Positif \\
& DF & Batas terendah 1,0, batas tertinggi 2,03 \\
& X2/DF & \\
& Icremental Fit Indices & \\
& - GFI & Nilai Berkisar 0-1, mendekati 1 semakin baik \\
& - AGFI & \\
& - TLI & \\
& - CFI & \\
& Icremental Fit Indices & \\
& - RMR & \\
& - RMSEA & \\
& Parsimony Fit Indices & \\
& - PNFI & \\
& - PCFI & Nilai Berkisar 0-1 \\
\hline
\end{tabular}

Sumber : (Sari, Salamah, \& Albetris, 2019)

Hasil dari pengolahan AMOS pada penelitian ini adalah :

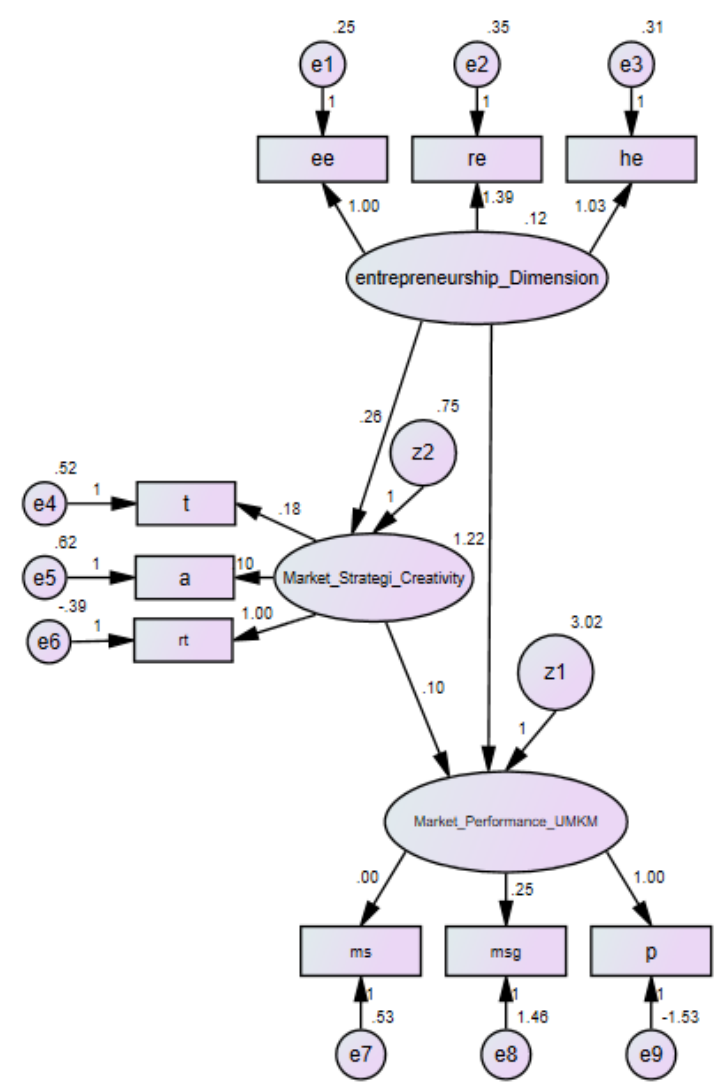

Gambar 1

Hasil Pengujian Full Model-Structural Equation Model (SEM)

Hasil pengujian model adalah :

1. Absolute Fit Indices

1) Hasil dari DF adalah 24 yang dimaknai "diterima" dikarenakan bernilai positif

2) Hasil dari $X 2 / \mathrm{DF}$ adalah 1,729 yang dimaknai "diterima" dikarenakan Batas terendah 1,0, batas tertinggi 2,03 
2. Icremental Fit Indices

1) Hasil dari GFI $=0,958$, AGFI $=0,920$, TLI $=0,820$ dan CFI $=0,791$ yang dimaknai "diterima" dikarenakan berada pada kriteria Nilai Berkisar 0-1, mendekati 1 semakin baik

2) Hasil dari $\mathrm{RMR}=0,040$ dan $\mathrm{RMSEA}=0,000$ yang dimaknai "diterima" dikarenakan berada pada kriteria < 0,08

3. Parsimony Fit Indices

Hasil dari PNFI $=0,527$ dan PCFI $=0,667$ yang dimaknai "diterima" dikarenakan berada pada kriteria Nilai

Berkisar 0 -.1

Hasil pengujian model di atas, dihasilkan bahwa Model pada penelitian ini bisa diterima.

Pengujian Hipotesis pada penelitian ini dengan menggunakan perbandingan hasil dari Critika Ratio dan P. Dengan kriteria nilai dari Critical Ratio $\geq 1,96$ atau nilai $\mathrm{P}$ adalah di bawah 0,05 . Hasil dari pengujian hipotesis dapat dilihat pada Tabel 2 di bawah ini :

Tabel 2

Hasil Pengujian Model

\begin{tabular}{lclrrrr}
\hline & & & Estimate & S.E. & C.R. & P \\
\hline Kreatifitas Strategi Pasar & $\leftarrow$ & Dimensi Kewirausahaan & .255 & .236 & 1.080 & .280 \\
Kinerja Pemasaran UMKM & $\leftarrow$ & Kreatifitas Strategi Pasar & .101 & .292 & .344 & .731 \\
Kinerja Pemasaran UMKM & $\leftarrow$ & Dimensi Kewirausahaan & 1.217 & .596 & 2.043 & .041 \\
\hline
\end{tabular}

Sumber: data olahan

Hasil dari pengujian Hipotesis adalah :

1. Pengujian Hipotesis antara Dimensi Kewirausahaan Terhadap Kreatifitas Strategi Pasar adalah dengan hasil CR $=1,080$ dan $\mathrm{P}$ adalah $=0,280$. Dengan kesimpulan bahwa Dimensi Kewirausahaan berpengaruh positif Terhadap Kreatifitas Strategi Pasar dapat diterima tetapi tidak signifikan. Dikarenakan tidak memenuhi kriteria dimana $\mathrm{CR}<1,96$ dan $\mathrm{P}>0,05$

2. Pengujian Hipotesis antara Kreatifitas Strategi Pasar Terhadap Kinerja Pemasaran UMKM adalah dengan hasil $\mathrm{CR}=0,344$ dan $\mathrm{P}$ adalah $=0,731$. Dengan kesimpulan bahwa Kreatifitas Strategi Pasar berpengaruh positif Terhadap Kinerja Pemasaran UMKM dapat diterima tetapi tidak signifikan. Dikarenakan tidak memenuhi kriteria dimana $\mathrm{CR}<1,96$ dan $\mathrm{P}>0,05$

3. Pengujian Hipotesis antara Dimensi Kewirausahaan Terhadap Kinerja Pemasaran UMKM adalah dengan hasil $\mathrm{CR}=2,043$ dan $\mathrm{P}$ adalah $=0,041$. Dengan kesimpulan bahwa Dimensi Kewirausahaan berpengaruh positif dan signifikan Terhadap Kinerja Pemasaran UMKM dapat diterima. Dikarenakan memenuhi kriteria dimana CR $\geq$ 1,96 dan $\mathrm{P}<0,05$

\section{Analisis Pengaruh Langsung, Pengaruh Tidak Langsung dan pengaruh Total}

Analisis pengaruh Langsung, Pengaruh Tidak Langsung dan pengaruh Total digunakan untuk melihat bagaimana pengaruh antara masing masing konstruk. Pengaruh langsung atau direct effect merupakan pengaruh dengan menggunakan anak panah satu ujung. Pengaruh Tidak langsung atau indirect effect merupakan pengaruh yang timbul dikarenakan adanya dampak dari pengaruh variabel diantaranya. Pengaruh Total atau total effect merupakan pengaruh dan efek dari berbagai hubungan yang ada dalam model penelitian.

Tabel 3

Pengaruh Total (Total Effect)

\begin{tabular}{|c|c|c|c|}
\hline & Dimensi Kewirausahaan & $\begin{array}{c}\text { Kreatifitas Strategi } \\
\text { Pasar }\end{array}$ & Kinerja Pemasaran UMKM \\
\hline Kreatifitas Strategi Pasar & .100 & .000 & .000 \\
\hline Kinerja Pemasaran UMKM & .236 & .049 & .000 \\
\hline
\end{tabular}

Sumber: data olahan

Tabel 4

Pengaruh Langsung (Direct Effect)

\begin{tabular}{lcccr}
\hline & Dimensi Kewirausahaan & $\begin{array}{c}\text { Kreatifitas Strategi } \\
\text { Pasar }\end{array}$ & Kinerja Pemasaran UMKM \\
\hline Kreatifitas Strategi Pasar & .100 & .000 & .000 \\
Kinerja Pemasaran UMKM & .231 & .049 & .000 \\
\hline
\end{tabular}


Tabel 5

Pengaruh Tidak Langsung (Indirect Effect)

\begin{tabular}{lcccr}
\hline & Dimensi Kewirausahaan & $\begin{array}{c}\text { Kreatifitas Strategi } \\
\text { Pasar }\end{array}$ & Kinerja Pemasaran UMKM \\
\hline Kreatifitas Strategi Pasar & .000 & .000 & .000 \\
Kinerja Pemasaran UMKM & .005 & .000 & .000 \\
\hline
\end{tabular}

Sumber: data olahan

Hasil Tabel 3, 4 dan 5 dibuatkan kesimpulan dari masing masing pengaruh ke dalam sebuah matrik:

Tabel 6

Matrik Koefisien Jalur Pengaruh Total, Pengaruh Langsung dan Pengaruh Tidak Langsung

\begin{tabular}{|c|c|c|c|}
\hline Uraian & $\begin{array}{l}\text { Pengaruh } \\
\text { Langsung }\end{array}$ & $\begin{array}{l}\text { Pengaruh Tidak } \\
\text { Langsung }\end{array}$ & $\begin{array}{l}\text { Pengaruh } \\
\text { Total }\end{array}$ \\
\hline $\begin{array}{l}\text { Pengaruh Dimensi Kewirausahaan Terhadap Kinerja Pemasaran } \\
\text { UMKM }\end{array}$ & 0,231 & 0,005 & .236 \\
\hline $\begin{array}{l}\text { Pengaruh Dimensi Kewirausahaan Terhadap Kreatifitas Strategi } \\
\text { Pasar }\end{array}$ & 0,100 & - & 0,100 \\
\hline $\begin{array}{l}\text { Pengaruh Kreatifitas Strategi Pasar terhadap Kinerja Pemasaran } \\
\text { UMKM }\end{array}$ & 0,049 & - & 0,049 \\
\hline
\end{tabular}

Sumber: data olahan

Tabel 6 menjelaskan bahwa:

1. Pengaruh langsung antara Dimensi Kewirausahaan Terhadap Kinerja Pemasaran UMKM adalah sebesar 0,231. Pengaruh tidak langsung adalah Dimensi Kewirausahaan melalui Kreatifitas Strategi Pasar terhadap Kinerja Pemasaran UMKM adalah 0,005. Hal ini dimaknai bahwa Pengaruh langsung > Pengaruh tidak Langsung (0,231 $>0,005)$. Sehingga dapat diartikan dalam penelitian ini bahwa Kreatifitas Strategi Pasar merupakan variabel yang tidak dapat memediasi Dimensi Kewirausahaan terhadap Kinerja Pemasaran UMKM.

2. Pengaruh Dimensi Kewirausahaan Terhadap Kinerja Pemasaran UMKM adalah sebesar 0,231 atau $23,1 \%$.

3. Pengaruh Dimensi Kewirausahaan Terhadap Kreatifitas Strategi Pasar adalah sebesar 0,100 atau $10 \%$.

4. Pengaruh Kreatifitas Strategi Pasar terhadap Kinerja Pemasaran UMKM adalah 0,049 atau 4,9\%

\section{Simpulan}

Pengujian hipotesis dari dimensi kewirausahaan terhadap kinerja pemasaran UMKM adalah dengan hasil CR = 2,043 dan $\mathrm{P}$ adalah = 0,041. Didapatkan bahwa dimensi kewirausahaan berpengaruh positif dan signifikan terhadap kinerja pemasaran UMKM dapat diterima. Besarnya pengaruh dari dimensi kewirausahaan terhadap kinerja pemasaran UMKM adalah 0,231 atau 23,1\%, sehingga dibutuhkan adanya penunjang dimensi kewirausahaan untuk meningkatkan market performance UMKM.

\section{Daftar Pustaka}

Alvarez, S.A., Barney, J.B. \& Newman, A.M.B. 2015, The poverty problem and the industrialization solution. Asia Pac J Manag 32, 23-37. https://doi.org/10.1007/s10490-014-9397-5

Edwin Cahya Ningrum Setyawati, Hari Susanta Nugraha dan Ilham Ainuddin, 2013, Karakteristik Kewirausahaan Dan Lingkungan Bisnis Sebagai Faktor Penentu Pertumbuhan Usaha (Studi IKM di Sentra Kerajinan Rotan Amuntai Kab. Hulu Sungai Utara, Provinsi Kalimantan Selatan), Jurnal Administrasi Bisnis, 2(1), https://doi.org/10.14710/jab.v2i1.5353

Elizar, Suripin, \& Wibowo, M. A. 2017. Model of Construction Waste Management Using AMOS-SEM for Indonesian Infrastructure Projects. MATEC Web of Conferences, 138. https://doi.org/10.1051/matecconf/201713805005

Ferdinand, A. 2005. Modal Sosial dan Keunggulan Bersaing: Wajah Sosial Strategi Pemasaran. Documentation, Diponegoro University Press, Semarang

Haroon, M \& Kocak, A. 2011. The Relationship Between Entrepreneurial Orientation Dynamic Capabilities and Firm Performance: An Exploratory Study of Small Turkish Firms. International Journal Business and Globalisation (IJBG), 7(3) https://doi.org/10.1504/IJBG.2011.042063

Naili Farida. 2016. Determinants Of Marketing Performance: Innovation, Market Capabilities And Marketing Performance. Jurnal Dinamika Manajemen, 7(1), 56-65

Paulina, I \& Wardoyo. 2012. Faktor Pendukung terhadap Intensi Berwirausaha pada Mahasiswa. Jurnal Dinamika Manajemen. 3(1), 1-10 
Rizwan Qaiser Danish, Javeria Asghar, Zeeshan Ahmad and Hafiz Fawad Ali, 2019, Factors affecting entrepreneurial culture: the mediating role of creativity. Journal of Innovation and Entrepreneurship. 8(14) https://doi.org/10.1186/s13731-019-0108-9

Simpeh, K. N. 2011. Entrepreneurship Theories and Empirical Research: A Summary Review of The Literature. Journal of Business and Management, 3(6), 1-9.

Sari, A. E., Salamah, S., \& Albetris, A. 2019. Dampak Dimensi Intellectual Capital Terhadap Knowledge Management Pendamping Desa di Kabupaten Kerinci. J-MAS (Jurnal Manajemen Dan Sains), 4(2), 220. https://doi.org/10.33087/jmas.v4i2.102

Saeko, A. N., Chuntarung \& Thoumrungroje, P. 2012. The Impact of Integrated Marketing Strategy on Mareting Performance: An Empirical Evidence From Exporting Business in Thailand. International Journal of Business Strategy. 12(4), 56-73

Steven Si, David Ahlstrom, Jiang Wei \& John Cullen, 2019, Business, Entrepreneurship and Innovation Toward Poverty Reduction, Entrepreneurship \& Regional Development, https://doi.org/10.1080/08985626.2019.1640485

Undang-undang Nomor 20 Tahun 2008 tentang Usaha Mikro, Kecil dan Menengah.

Wincent, J., Thorgren, S., \& Anokhin, S., 2014. Entrepreneurial orientation and network board diversity in network organizations. Journal of Business Venturing, 29(2), 327-344. https://doi.org/10.1016/j.jbusvent.2013.04.002 